\title{
The Role of Gestational Diabetes Mellitus and Pelvic Floor 3D-Ultrasound Markers at the Second and Third Trimester of Pregnancy Predicting 6-18 Months Postpartum Urinary Incontinence: Preliminary Results From a Prospective Cohort
}

Carlos Izaias Sartorão Filho

São Paulo State University

Fabiane Affonso Pinheiro

São Paulo State University

Luiz Takano

São Paulo State University

Raghavendra Hallur Lakshmana Shetty

São Paulo State University

Sthefanie K. Nunes

São Paulo State University

Adriely Bittencourt Morgenstern Magyori

São Paulo State University

Claudia G. Magalhães

São Paulo State University

Baerbel Junginger

Charité - University Medicine Berlin

Zsuzsanna Ilona Katalin de Jármy Di Bella

Federal University of São Paulo

Iracema M P Calderon

São Paulo State University

Angélica M P Barbosa

São Paulo State University

Marilza Vieira Cunha Rudge ( $\nabla$ marilzarudge@gmail.com )

São Paulo State University

Research Article

Keywords: Pelvic Floor, Gestational Diabetes Mellitus, Urinary Incontinence, Ultrasound 
Posted Date: November 1st, 2021

DOl: https://doi.org/10.21203/rs.3.rs-985987/v1

License: (c) (i) This work is licensed under a Creative Commons Attribution 4.0 International License. Read Full License 


\section{Abstract \\ Background}

Gestational Diabetes Mellitus and long-term urinary incontinence (UI) have a severe impact on women's health. New methods to identify pregnant predictor risk factors of UI are needed. Our study investigated clinical and pelvic floor 3D-ultrasound markers in pregnant women at the second and third trimesters to predict 6-18 months postpartum UI.

\section{Methods}

This ongoing prospective cohort study included one hundred five nulliparous pregnant women with universal GDM screening and diagnosis, treated with nutritional and healthy lifestyle intervention. Pelvic floor 3DUltrasound was performed at the second and third trimesters of gestation. Clinical and pelvic floor 3DUltrasound biometry were collected. The ICIQ-SF and ISI questionnaires for UI were applied in the third trimester and 6-18 months postpartum. We performed univariate analysis $(P<.20)$ to extract risk factors variables and multivariate logistic regression analysis $(P<.05)$ to obtain the adjusted relative ratio for 6-18 months postpartum UI.

\section{Results}

In a preliminary result, a total of 93 participants concluded the follow-up. Using the variables obtained by the univariate analysis and after the adjustments for potential confounders, logistic regression analysis revealed that Gestational Diabetes Mellitus exposure was a strong and independent risk factor for 6-18 months postpartum UI (Adjusted RR 8.088; 95\% Cl 1.17-55.87; P..034). In addition, higher hiatal area distension at rest from the second to the third trimester was negatively correlated with 6-18 months postpartum UI (Adjusted RR 0.966; 95\% Cl 0.93-0.99; P. .023).

\section{Conclusion}

Gestational Diabetes Mellitus was positively correlated with 6-18 months postpartum UI, and a higher hiatal area distension was negatively correlated with 6-18 months postpartum UI development.

\section{Trial registration:}

Regulatory approval was obtained from the Institutional Review Board (number 1.716.895) by "Botucatu Medical School of São Paulo State University (Unesp)" Ethics Committee.

\section{Introduction}


Gestational diabetes mellitus (GDM) significantly increases both the adverse short-term maternal and perinatal outcomes and the likelihood of long-term type 2 Diabetes Mellitus, cardiovascular disease, and Urinary Incontinence (UI). [1-3] GDM and long-term UI share some standard pathophysiological features. Both combined disorders seem to have hyperglycemic Pelvic Floor Muscle (PFM) and Rectus Abdominis Muscle (RAM) myopathy as the underlying mechanism. [1, 4-7] Specifically, current clinical and experimental studies suggest that Pregnancy Specific-UI (PS-UI) is the earliest symptom of hyperglycemic PFM and RAM myopathy during pregnancy, despite overlooked complaints during prenatal care assistance. [5, 7-10] Nevertheless, a previous study showed that PS-UI, the severity of long-term UI, and the negative impact of UI on quality of life are more significant among GDM pregnant women in the first year postpartum. [5] However, none of these studies correlated the clinical pregnancy data and PFM ultrasound assessment in the third trimester as predictors of 6-18 months postpartum UI.

The translabial three-dimensional ultrasonography (3DUS) provides an adequate and reliable evaluation of anatomical and functional PFM status. [11] However, few studies explored the 3DUS behavior of PFM in pregnancy and the adverse clinical outcomes after pregnancy. [12] Previously, we demonstrated that GDM women had lower Hiatal Area (HA) biometry changes from 24 to 38 weeks of pregnancy than nonGDM women. It seems highly likely that GDM alters the maternal adaptation during the pregnancy of PFM structures assessed by 3DUS, decreasing the distensibility of PFM at the end of the pregnancy. [6]

Reports confirm that GDM and UI are two clinical entities with substantial social and economic burdens associated with significant direct and indirect public health costs. [13] GDM has a tremendous impact on the mother's health and represents a harbinger of the vicious cycle of diabetes. [14] Despite these observations, the link between GDM and long-term UI remains mostly unexplored. Thus, developing 3DUS markers of hyperglycemic myopathy during pregnancy as predictors of long-term $\mathrm{Ul}$ is crucial. We hypothesized that GDM damages the pelvic floor muscle (PFM) during pregnancy $[5,6]$, leading to the adverse clinical outcome of PS-UI. The triad proposed by Rudge et al., characterized by hyperglycemic PFM, RAM myopathy, and PS-UI, impacts long-term UI's prevalence and severity. [4] The development of a predictive test during pregnancy for long-term UI collaborates to identify a high-risk population accurately. Thus, this study aimed to identify clinical and PF 3DUS markers in pregnant women's second and third trimesters as 6-18 months postpartum predictors of UI.

\section{Methods}

This ongoing prospective non-interventional cohort study started in 2015 in the Perinatal Diabetes Research Centre (PDRC), Botucatu Medical School-UNESP. One hundred five participants were enrolled.

Eligibility criteria: Nulliparous, adults, singleton pregnancy, universal GDM screening, and PFM 3DUS examination, without severe comorbidities. Exclusion criteria: women exposed to the active second phase of labor, vaginal birth, pre-gestational diabetes, pre-gestational UI, preterm birth, hypoglycemic drugs, new pregnancy during postpartum follow-up. We also considered only pregnant women with mild GDM, regularly controlled with nutritional and lifestyle interventions, to avoid the confoundment of the 
pharmacotherapy on the results. Moreover, we considered only those submitted to C-section before the second period of labor to prevent the recognized interference of parturition in the outcome Ul. We calculated the sample size using the prevalence of long-term $\mathrm{Ul}$ in non-GDM of 18\%, [1] the relative risk of $\mathrm{UI}$ in the GDM group of 2.73 [2], a type 2 error of $20 \%$, and a $95 \%$ confidence interval, resulting in 33 participants per group. Statistical analyses were performed using the software SPSS 23.0 (IBM, NY).

Eligible women were included between 24-28 weeks of gestation, completed a detailed questionnaire on sociodemographic information, past medical, regular physical activity (150 minutes/week), initial pregnancy weight in $\mathrm{Kg}$, height in $\mathrm{cm}$, Body Mass Index, and a physical examination. Ethnicity was defined as Caucasian or non-Caucasian. The same researcher performed a PFM transperineal 3DUS at 24-28 and 36-40 weeks of gestation (CISF). The 3DUS data imaging was stored for posterior blinded and offline analysis. Long-term follow-up continued until April 2020. The same clinical and anthropometric evaluation was done at 36-40 weeks of gestation.

The fasting plasma glucose in the first trimester in $\mathrm{mg} / \mathrm{dL}, 75$ grams-Oral Glucose Tolerance Test (OGTT) in the second trimester of pregnancy, gestational age (in weeks) at the two-time points of 3DUS, the ISI, and the ICIQ-SF questionnaire scores for PS-UI at 36-40 weeks of pregnancy were recorded. In addition, at 6-18 months after C-section, breastfeeding duration, regular physical activity, postpartum smoking, newborn weight, and gestational age at delivery, to classify newborn as appropriate, large or small for gestational age, and the occurrence of Urinary Incontinence plus ISI and ICIQ-SF severity scores were collected.

The primary outcome was the occurrence of UI between 6-18 months after the C-section. In addition, we investigated the association between $\mathrm{UI}$ and the risk factors, including maternal and perinatal characteristics, the first-trimester fasting glucose, and the OGTT results as positive or negative for GDM diagnosis, the occurrence and severity PS-UI, and the PFM 3DUS biometry.

Women included in this study with hyperglycemia in the second and third trimester of pregnancy met the Fasting Blood Glucose (FBG) criteria in the first trimester (1- 13 gestational weeks) was lower than 5.1 mmol/L. [15] All pregnant women underwent 75-g OGTT between 24-28 weeks. The cutoffs were 92, 180, and $153 \mathrm{mg} / \mathrm{dL}$, respectively, fasting one and two hours after glucose overloading. The GDM was defined by one or more values equal to or more than the respective cutoffs. [16, 17] For mild GDM, a glucose profile was performed during a 1-day hospital stay with the woman on $2840 \mathrm{kcal}$-diet fractionated in five meals. Plasma glucose was measured every two hours, from 8 AM to 6 PM. The thresholds used were 90 $\mathrm{mg} / \mathrm{dL}$ for fasting (8h) and $130 \mathrm{mg} / \mathrm{dL}$ for any postprandial level. To maintain normoglycemia, all pregnant women received the same nutritional and lifestyle interventions as the cornerstone of treatment during the last 10-15 weeks of pregnancy. After these instructions, when glycemia remains elevated after 1-2 weeks of lifestyle interventions, daily glucose testing was continued, pharmacological treatment was initiated, and the patient was excluded from this study. The exposition and a follow-up period were at 2428 weeks of gestation (T1), 36-40 weeks (T2), birth, and 6-18 months after a planned C-section. PS-UI was considered as any urinary leakage that started during pregnancy. [18] 
The PF 3DUS examination was done according to the protocol proposed by Dietz et al. [11] at 24-28 weeks (T1) and 36-40 weeks (T2). The functional maneuvers were previously explained. The variables of 3DUS in T1 and T2, at rest, contraction, and distension, were collected after completing the study, offline, by the same observer, blinded (CISF). The measurements: Hiatal area in square cm; Antero-Posterior (AP) diameter in cm; Transversal diameter in cm; variation of AP from T1-T2 in cm; variation of Hiatal Area T1$\mathrm{T} 2$ in square cm; variation of Transversal diameter from T1-T2 in cm; the relationship between rest and contraction in T1, in T2 and the T1-T2 variation from all biometry; the relationship between rest and distension in T1, T2, and the T1-T2 variation; the relationship between contraction and distension in T1, T2, and the T1-T2 variation; the percentual variation from each biometry analysis were calculated. $[6,19]$ We used the GE Voluson system with a volumetric curved array three-dimensional transducer (GE Healthcare, Zipf, Austria).

\section{Statistical Analysis}

Descriptive analysis was applied for the demographic characteristics described as mean \pm standard deviation (SD) and Minimum / Maximum values. We first used the Cox univariate logistic regression analysis to test the association between each risk factor and the 6-18 months postpartum UI. Then, factors with a $P$-value under .20 were included in a multivariate logistic regression analysis. All significant maternal-pregnancy characteristics and the PFM 3DUS measurements from the univariate analysis were used as predictors. A multivariate logistic regression analysis after adjustments for potential confounding factors to identify the relationship between 6-18 months postpartum $\mathrm{UI}$ and clinical plus PFM 3DUS at the second and third trimesters of pregnancy was performed. Relative risk (RR) and 95\% confidence intervals $(95 \% \mathrm{Cl})$ were reported. The RR and $95 \% \mathrm{Cl}$ were calculated for each clinical and 3DUS measure and adjusted for all other variables. These variables were excluded one by one (models 1 to 8 ) until reaching the final best model, which was defined by the impossibility to exclude any other variable without significant loss in adjustment. For all multivariate logistic tests, a $P$-value under .05 was considered.

\section{Results}

A total of 105 participants were enrolled in the study, 52 in the GDM group and 53 in the non-GDM group. Finally, 93 women met eligibility (Figure 1).

Table 1 represents the baseline clinical characteristics of the overall population. 
Table 1

Baseline Clinical Characteristics of Participants: $\mathrm{N}=93$

\begin{tabular}{|lll|}
\hline & MEAN & SD \\
\hline Age (Years) & 26.4 & 4.8 \\
\hline Prepregnancy maternal weight (kg) & 70.2 & 15.8 \\
\hline Prepregnancy Body Mass Index & 26.2 & 5.3 \\
\hline Pregnancy weight gain (kg) & 10.0 & 4.9 \\
\hline Gestational age at T1 (weeks) & 26.9 & 1.0 \\
\hline Gestational age at T2 (weeks) & 36.4 & 0.7 \\
\hline T1-T2 interval (weeks) & 9.6 & 1.1 \\
\hline FB Glucose at first trimester (mg/dl) & 83.6 & 9.1 \\
\hline 75g-OGTT-fasting (mg/dl) & 81.5 & 12.2 \\
\hline 75g-OGTT-1hour (mg/dl) & 128.2 & 35.2 \\
\hline 75g-OGTT-2hours (mg/dl) & 115.0 & 26.8 \\
\hline Gestational ICIQ-SF score & 4.9 & 5.5 \\
\hline Gestational ISI score & 2.13 & 2.28 \\
\hline Newborn weight (kg) & 3.143 & .394 \\
\hline Postpartum weight (kg) & 74.07 & 17.48 \\
\hline Breastfeeding (months) & 6.97 & 3.49 \\
\hline Postpartum IClQ-SF score & 1.48 & 4.04 \\
\hline SD: Standard Deviation & & \\
\hline (wa & & \\
\hline
\end{tabular}

Min: Minimum value; Max: Maximum value

T1: 24-28 weeks of gestation; T2: 36-40 weeks of gestation; T1-T2: the period between T1 to T2

FB Glucose: Fasting Blood Glucose

ICIQ-SF: International Consultation on Incontinence Questionnaire - Short Form

Gestational ISI: Incontinence Severity Index during pregnancy

The mean age was 26.4 years $( \pm 4.8)$, the prepregnancy body weight was $70.2 \mathrm{Kg}( \pm 15.8)$, weight gain was $10.0 \mathrm{Kg}( \pm 4.9)$; the mean gestational age at $\mathrm{T} 1$ was $26.9( \pm 1.0)$, at $\mathrm{T} 2,36.4( \pm 0.7)$, and the interval T1-T2 $9.6( \pm 1.1)$ weeks; the mean of fasting glucose at the first trimester was $83.6( \pm 9.1) \mathrm{mg} / \mathrm{dL}$; the 
75g-OGTT fasting $(\mathrm{mg} / \mathrm{dL})$, one hour and two hours were $81.5( \pm 12.2) ; 128.2( \pm 35.2) ; 115.0( \pm 26.8)$ respectively. The ICIQ-SF gestational score was $4.9( \pm 5.5)$, and ISI gestational score was $2.13( \pm 2.28)$. The newborn weight, 3143 grams $( \pm 394)$, maternal postpartum weight, $74.07( \pm 17.49)$, breastfeeding duration, $6.97( \pm 3.49)$ months, and the postpartum ICIQ-SF score was $1.48( \pm 4.04)$.

Table 2 reports the 3DUS measurements at T1 and T2. The crucial findings were the HA in square $\mathrm{cm}$ at $\mathrm{T} 1$ at rest, contraction and distension was $13.5( \pm 2.1), 12.4( \pm 3.7)$, and $15.1( \pm 2.8)$, respectively; at T2, $14.5( \pm 2.2), 13.8( \pm 3.4)$, and $16.5( \pm 3.0)$, respectively.

Table 2

Translabial 3DUS Biometry During Pregnancy. $\mathrm{N}=93$

\begin{tabular}{|lllllll|}
\hline \multicolumn{2}{|l}{ REST CONTRACTION DISTENSION } & & & & \\
\hline & $\mathrm{M}$ & $\mathrm{SD}$ & $\mathrm{M}$ & $\mathrm{SD}$ & $\mathrm{M}$ & $\mathrm{SD}$ \\
\hline Antero-posterior T1 & 5.6 & 0.7 & 5.1 & 0.8 & 5.6 & 0.7 \\
\hline Antero-posterior T2 & 5.8 & 0.7 & 5.1 & 0.9 & 5.9 & 0.6 \\
\hline Antero-posterior T1-T2 & 0.2 & 0.5 & 0.0 & 0.7 & 0.2 & 0.6 \\
\hline Transversal T1 & 3.9 & 0.4 & 3.9 & 0.5 & 4.6 & 4.8 \\
\hline Transversal T2 & 4.0 & 0.4 & 4.0 & 0.6 & 4.3 & 0.5 \\
\hline Transversal T1-T2 & 0.1 & 0.3 & 0.2 & 0.5 & -0.4 & 4.8 \\
\hline Hiatal area T1 & 13.5 & 2.1 & 12.4 & 3.7 & 15.1 & 2.8 \\
\hline Hiatal area T2 & 14.5 & 2.2 & 13.8 & 3.4 & 16.5 & 3.0 \\
\hline Hiatal area T1-T2 & 1.0 & 1.5 & 1.3 & 2.4 & 1.4 & 2.6 \\
\hline
\end{tabular}

M: mean; SD: standard deviation;

T1: 24-28 weeks of gestation; T2: $36-40$ weeks of gestation; T1-T2: the interval between T1 to T2 Antero-posterior and Transversal diameter in $\mathrm{cm}$.

Hiatal area in cm square.

Table 3 demonstrates the percentual variation of 3DUS from T1 to T2. The primary feature is the T1-T2 percentual variation of HA from distension to contraction maneuvers, with a mean of -46.8 (SD 28.5). 
Table 3

Percentual Variation of Translabial 3DUS Biometry during Pregnancy. $\mathrm{N}=93$

\begin{tabular}{|llllllll|}
\hline & \multicolumn{2}{c}{ \%CONTRACTION } & \multicolumn{2}{c}{ \% DISTENSION-REST } & \multicolumn{2}{c|}{ \% DISTENSION- } \\
& -REST & & & & \multicolumn{2}{c|}{ CONTRACTION } \\
\hline & M & SD & M & SD & & M \\
\hline T1 antero-posterior & -8.4 & 15.8 & 1.3 & 13.6 & 12.2 & 16.3 \\
\hline T1 transversal & -0.2 & 14.9 & 19.7 & 12.3 & 22.3 & 13.0 \\
\hline T1 hiatal area & -6.9 & 29.7 & 12.5 & 20.1 & 72.6 & 29.3 \\
\hline T2 antero-posterior & -12.4 & 16.0 & 18.8 & 19.3 & 18.8 & 19.3 \\
\hline T2 transversal & 0.0 & 15.4 & 8.5 & 16.7 & 8.5 & 16.7 \\
\hline T2 hiatal area & -3.2 & 27.5 & 25.8 & 34.4 & 25.8 & 34.4 \\
\hline T1-T2 antero-posterior & -4.0 & 12.3 & 17.5 & 23.5 & 6.6 & 16.0 \\
\hline T1-T2 transversal & 0.2 & 13.0 & -11.3 & 12.3 & -13.8 & 12.9 \\
\hline T1-T2 hiatal area & 3.7 & 18.0 & 13.2 & 37.2 & -46.8 & 28.5 \\
\hline M: Mean & & & & & & \\
\hline
\end{tabular}

SD: Standard deviation

Min: minimum value

Max: maximum value

All variables disposed of in \%

T1: 24-28 weeks of gestation; T2: 36-40 weeks of gestation

Table 4 demonstrates Cox univariate and multivariate logistic regression analysis among clinical and $\mathrm{HA}$ measurements and 6-18 months postpartum UI. The Ul risk was 5.4 times higher in women with positive 75g-OGTT; it decreased with increased weight gain; it decreased with an increased variation from T1-T2 in transversal diameter and HA at rest; it was 3.6 times higher in women who had PS-UI. All the variables with a $P$-value under .20 in the univariate were included in the multivariate regression analysis. We did not use the variable weight gain because its clinical interpretation was inconsistent; univariate demonstrates that a higher weight gain was related to a lower RR for 6-18 months postpartum UI, a condition not observed clinically. The multivariate analysis was performed after adjustments for GDM; PS-UI diagnosis; superior educational level; variation from $\mathrm{T} 1$ to $\mathrm{T} 2$ of transversal diameter and HA at rest; percentual variation of $\mathrm{HA}$ from contraction to rest and from distension to rest at T2; percentual variation of HA from contraction to rest and from distension to rest from T1 to T2; gestational ICIQ-SF and ISI scores; and newborn weight (model 1, the full model). In the backward model, some variables were eliminated, 
avoiding collinearity. Also, after adjustments for the newborn weight (model 2, P. .992), gestational ICIQSF (model 3; $P$. .778), the percentual of HA variation from contraction to rest at T2 (model 4; $P$. .576), PS$\mathrm{UI}$ (model 5; $P:$.296), the variation from T1-T2 of transversal diameter at rest (model 6; $P$. .228), and for the percentual variation from T1 to T2 of HA from contraction to rest (model 7; $P$. .093). Adjusted analysis of potential confounders disclosed that 6-18 months postpartum UI development was significantly associated with GDM (model 8; Adjusted RR: 8.08; 95\% Cl 1.17-55.8; P. .034) and the percentual variation from T1 to T2 of the HA from distension to rest (model 8, the Best model; Adjusted RR: 0.96; 95\% Cl 0.93 - 0.99; P. .023).

\section{Table 4: Clinical and Hiatal Area measurements. Cox univariate and multivariate logistic regression analysis among 6-18 months postpartum $\mathrm{Ul} . \mathrm{N}=93$}

For univariate Cox Linear Regression, $P$-value:.20

T1: 24-28 weeks of gestation; T2: 36-40 weeks of gestation

ICIQ-SF: International Consultation on Incontinence Questionnaire - Short Form

PS-UI: Pregnancy specific urinary incontinence; Gestational ISI: Incontinence Severity Index during pregnancy

For multivariate logistic regression, $P$-value: .05

Best model obtained after 8 Backward elimination methods.

The percentual Hiatal Area distension-contraction at T2 was excluded for collinearity with other variables.

RR: Relative Risk; Adj RR: Adjusted Relative Risk; 95\% Cl: 95\% Confidence Interval

\section{Discussion}

First, we observed that GDM, even the mild presentation, treated only with nutritional and healthy lifestyle interventions, is a solid and independent risk factor for 6-18 months postpartum UI. Second, the higher PF HA distensibility in the third trimester of pregnancy is protective against 6-18 months postpartum UI. Consistent with these findings, our study reports a positive relation between GDM and increased 6-18 months postpartum $\mathrm{Ul}$ and a negative relation between higher HA distension and decreased 6-18 months postpartum UI. Thus, both markers are opposed, as GDM is a causative agent, and the higher HA distensibility observed by 3DUS is a protective agent for 6-18 months postpartum UI development.

Pregnancy has been considered "an underutilized window of opportunity to improve long-term maternal and infant health." [20] GDM diagnosis finds a group of women and their offspring at higher risk of diabetes, obesity, and premature cardiovascular disease in the long term. [21] The role of GDM in the later development of $\mathrm{UI}$ is limited in the classical literature. [21, 22] Multivariate regression analyses revealed that GDM, even when mild, was a solid and independent risk factor for 6-18 months postpartum UI 


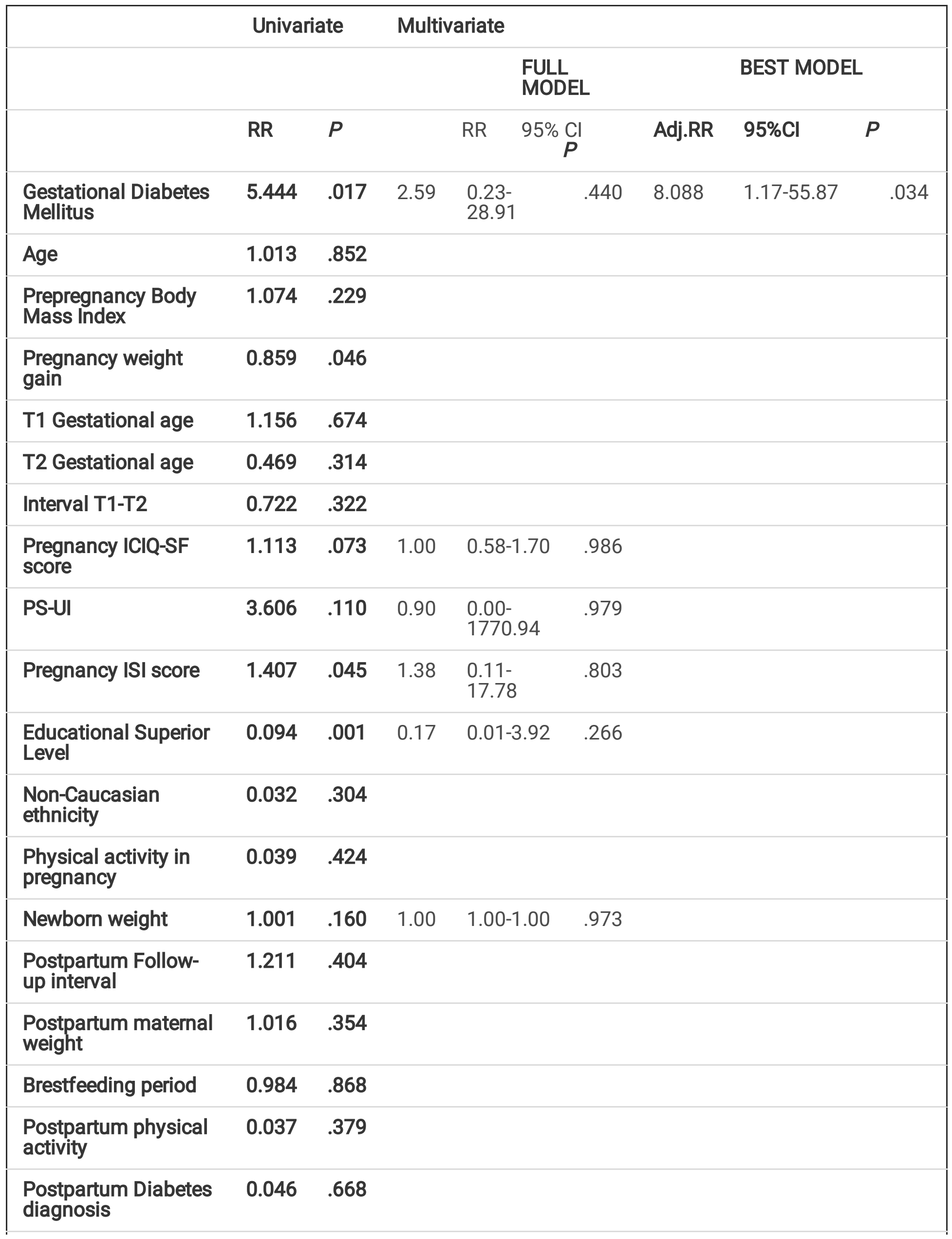




\begin{tabular}{|c|c|c|c|c|c|c|c|c|}
\hline $\mathrm{T} 1$ at Rest & 1.037 & .820 & & & & & & \\
\hline T1 at Contraction & 1.054 & .572 & & & & & & \\
\hline T1 at Distension & 1.062 & .620 & & & & & & \\
\hline T2 at Rest & 0.896 & .482 & & & & & & \\
\hline T2 at Contraction & 1.122 & .214 & & & & & & \\
\hline T2 at Distension & 0.929 & .529 & & & & & & \\
\hline $\begin{array}{l}\text { Variation T1 to T2 at } \\
\text { Rest }\end{array}$ & 0.742 & .181 & 0.93 & $0.40-2.16$ & .868 & & & \\
\hline $\begin{array}{l}\text { Variation } \mathrm{T} 1 \text { to } \mathrm{T} 2 \text { at } \\
\text { Contraction }\end{array}$ & 1.125 & .347 & & & & & & \\
\hline $\begin{array}{l}\text { Variation T1 to T2 at } \\
\text { Distension }\end{array}$ & 0.849 & .206 & & & & & & \\
\hline $\begin{array}{l}\% \text { Contraction to Rest } \\
\text { T1 }\end{array}$ & 1.006 & .591 & & & & & & \\
\hline $\begin{array}{l}\% \text { Distension to Rest } \\
\mathrm{T} 1\end{array}$ & 1.007 & .685 & & & & & & \\
\hline $\begin{array}{l}\% \text { Distension to } \\
\text { Contraction T1 }\end{array}$ & 0.997 & .732 & & & & & & \\
\hline $\begin{array}{l}\text { \% Contraction to Rest } \\
\text { T2 }\end{array}$ & 1.016 & .110 & 0.98 & $0.91-1.05$ & .561 & & & \\
\hline $\begin{array}{l}\% \text { Distension to Rest } \\
\text { T2 }\end{array}$ & 0.978 & .090 & 0.98 & $0.91-1.05$ & .536 & & & \\
\hline $\begin{array}{l}\% \text { Distension to } \\
\text { Contraction T2 }\end{array}$ & 0.978 & .090 & & & & & & \\
\hline $\begin{array}{l}\text { T1-T2 \% Variation } \\
\text { Contraction to Rest }\end{array}$ & 1.023 & .111 & 1.06 & $0.97-1.15$ & .199 & & & \\
\hline $\begin{array}{l}\text { T1-T2 \% Variation } \\
\text { Distension to Rest }\end{array}$ & 0.983 & .077 & 0.96 & $0.89-1.05$ & .376 & 0.966 & 0.93-0.99 & .023 \\
\hline $\begin{array}{l}\text { T1-T2 \% Var. } \\
\text { Distension to } \\
\text { Contraction }\end{array}$ & 1.001 & .746 & & & & & & \\
\hline
\end{tabular}

(Adjusted RR 8.088; 95\% Cl 1.17-55.87, P. .034). Previous translational studies have demonstrated that mild GDM models are enough to cause myopathy in PFM or RAM [7-9] muscles directly involved in the urinary continence mechanisms. Thus, this association between GDM and UI development risk seems to result from transient hyperglycemia exposure of the PF muscles. [4] Furthermore, our findings add to previous clinical and experimental studies, suggesting hyperglycemic myopathy as the underlying mechanism between GDM and long-term UI. [4] 
In this study, the PF 3DUS assessment detected an increase in the PF HA distensibility at the end of the third trimester of pregnancy as a protective factor against 6-18 months postpartum Ul. This unexpected functional observation identifying a PFM becoming more distensible at the end of the third trimester of pregnancy is not previously reported in the literature.

The strengths of our study include the longitudinal design with a 1-2 years follow-up rate, considering GDM as a transient condition with lifelong consequences. The same author did all PFM 3DUS, blinded. We provided selection exclusion criteria as previous parity, labor induction, the second period of active labor, and vaginal delivery, the most considered postpartum UI risk factors. Finally, the statistical analyses considered all patients as a whole, without separation between GDM and non-GDM, and all GDM patients treated with hypoglycemic drugs were excluded. This analysis allows us to obtain the best model after eight backward models of multivariate analyses, confirming that even the mild GDM is a strong predictor of 6-18 months postpartum UI despite the short period of hyperglycemic status exposure. Limitations: First, the lost follow-up was randomly due to loss of contact information by cellphone number changes, a common situation in Brazil. Thus, most losses occurred at the outcome analysis on 6-18 months postpartum UI, and we considered our losses acceptable for a 1-2 year cohort. Second, our results may not be generalized to other populations, including those women with vaginal birth, multiparous, or GDM treated by insulin or other drugs. Third, our strict inclusion criteria of GDM women-only treated with nutritional and lifestyle interventions probably removed essential risk factors for 6-18 months postpartum UI. Fourth, we do not collect data on the prepregnancy and first trimester PFM 3DUS, as the enrollment occurred at the second trimester of gestation. Moreover, although we observed changes in the PFM function during the pregnancy span, more studies are demanded to explore these findings better.

Our preliminary results suggested that GDM diagnosis and PFM 3DUS functional analysis are good clinical indexes for postpartum UI prediction concerning GDM diagnosis and protective prediction of $\mathrm{UI}$ concerning higher distensibility of HA observed during pregnancy by 3DUS.

\section{Conclusion}

Our preliminary results provided objective data that GDM-pregnancies are positively related to increasing the risk for 6-18 months postpartum UI development, even in a population submitted to a planned Csection. Furthermore, mild GDM exposure is a solid and independent risk predictor for 6-18 months postpartum UI. While further studies are required to elucidate the mechanism, mild GDM may represent a modifiable risk factor when detected earlier in pregnancy. Opposite results were found for higher PFM 3DUS distensibility from the second to third trimesters as positively related to decreasing risk of 6-18 months postpartum UI. Further studies may be designed to determine the role and consequences for the PFM after childbirth.

\section{Declarations}


Ethics approval, guidelines and consent to participate: Regulatory approval was obtained from the Institutional Review Board (number 1.716.895) by "Botucatu Medical School of São Paulo State University (Unesp)" Ethics Committee. Written informed consent was obtained, and the participants were handled adequately for their morbidities. The Strobe Statement guideline was used for reporting the manuscript. All methods were carried out in accordance with relevant guidelines and regulations.

\section{Consent for publication: not applicable}

Availability of data and materials: the raw database file is provided as a supplementary submission file.

Fundings: Human resources and infrastructure of the PDRC Botucatu Medical School UNESP. This research was also granted by the Sao Paulo Research Foundation (FAPESP) \#2016/09710-9.

Acknowledgments: We thank all the participants enrolled in the study from the Diamater Research Group, Perinatal Diabetes Research Center, Department of Gynecology and Obstetrics, Tocogynecology Postgraduate Program Botucatu Medical School, UNESP.

Competing Interests: All authors declare no competing interests.

Author Contribution: CISF did all 3dUS exams, and BJ and ZIKJDB provided the revision images support. CISF, AMPB, IMPC, and MVCR wrote the mains manuscript text. FAP, LT, SKN, RHLS, ABMM, and CGM worked in the recruitment and survey process. All authors participated in the conception and revision of all research and manuscript process.

\section{References}

1. Barbosa AMP, Adriano Dias GM, Calderon IMP, Rudge MVC, Witkin S, Dias A, et al. Urinary incontinence and vaginal squeeze pressure two years post-cesarean delivery in primiparous women with previous gestational diabetes mellitus. Clinics [Internet]. 2011 [cited 2021 Jan 1];66(8):1341-5. Available from: https://pubmed.ncbi.nlm.nih.gov/21915481/

2. Chuang C-M, Lin I-F, Horng H-C, Hsiao Y-H, Shyu I-L, Chou P. The impact of gestational diabetes mellitus on postpartum urinary incontinence: a longitudinal cohort study on singleton pregnancies. BJOG An Int J Obstet Gynaecol [Internet]. 2012 Oct 1 [cited 2019 Sep 1];119(11):1334-43. Available from: http://doi.wiley.com/10.1111/j.1471-0528.2012.03468.x

3. Scholtens DM, Kuang A, Lowe LP, Hamilton J, Lawrence JM, Lebenthal Y, et al. Hyperglycemia and Adverse Pregnancy Outcome Follow-up Study (HAPO FUS): Maternal Gestational Diabetes Mellitus and Childhood Glucose Metabolism. Diabetes Care [Internet]. 2019 Mar;42(3):381-92. Available from: http://care.diabetesjournals.org/lookup/doi/10.2337/dc18-1646

4. Rudge MVC, Souza FP, Abbade JF, Hallur RLS, Marcondes JPC, Piculo F, et al. Study protocol to investigate biomolecular muscle profile as predictors of long-term urinary incontinence in women with gestational diabetes mellitus. BMC Pregnancy Childbirth [Internet]. 2020 Dec 19 [cited 2021 Jan 
1];20(1):117. Available from:

https://bmcpregnancychildbirth.biomedcentral.com/articles/10.1186/s12884-020-2749-x

5. Piculo F, Marini G, Vesentini G, Morceli G, Damasceno DC, Sobrevia L, et al. Pregnancy-specific urinary incontinence in women with gestational hyperglycaemia worsens the occurrence and severity of urinary incontinence and quality of life over the first year post partum. Eur J Obstet Gynecol Reprod Biol [Internet]. 2020 Sep;252:336-43. Available from: https://linkinghub.elsevier.com/retrieve/pii/S0301211520304036

6. Sartorão Filho Cl, Pinheiro FA, Prudencio CB, Nunes SK, Takano L, Enriquez EMA, et al. Impact of gestational diabetes on pelvic floor: A prospective cohort study with three-dimensional ultrasound during two-time points in pregnancy. Neurourol Urodyn [Internet]. 2020 Nov 28;39(8):2329-37. Available from: https://onlinelibrary.wiley.com/doi/10.1002/nau.24491

7. Vesentini G, Marini G, Piculo F, Damasceno DCC, Matheus SMMMM, Felisbino SLL, et al. Morphological changes in rat rectus abdominis muscle induced by diabetes and pregnancy. Brazilian J Med Biol Res [Internet]. 2018 Mar 1;51(4). Available from: http://www.scielo.br/scielo.php? script=sci_arttext\&pid=S0100-879X2018000400611\&lng=en\&tlng=en

8. Marini G, Piculo F, Vesentini G, Damasceno DC, Delella FK, Calderon IMP, et al. The influence of hyperglycemia on the remodeling of urethral connective tissue in pregnant rats. Eur $\mathrm{J}$ Obstet Gynecol Reprod Biol [Internet]. 2018 Feb [cited 2019 Aug 3];221:81-8. Available from: https://linkinghub.elsevier.com/retrieve/pii/S0301211517305821

9. Piculo F, Marini G, Barbosa AMP, Damasceno DC, Matheus SMM, Felisbino SL, et al. Urethral striated muscle and extracellular matrix morphological characteristics among mildly diabetic pregnant rats: translational approach. Int Urogynecol J [Internet]. 2014 Mar 17;25(3):403-15. Available from: http://link.springer.com/10.1007/s00192-013-2218-4

10. Chen B, Yeh J. Alterations in Connective Tissue Metabolism in Stress Incontinence and Prolapse. J Urol [Internet]. 2011 Nov [cited 2021 May 28];186(5):1768-72. Available from: http://www.jurology.com/doi/10.1016/j.juro.2011.06.054

11. Dietz HP. Pelvic Floor Ultrasound: A Review. Clin Obstet Gynecol [Internet]. 2017 Mar [cited 2019 Aug 4];60(1):58-81. Available from: http://www.ncbi.nlm.nih.gov/pubmed/28005595

12. Dietz HP, Scoti F, Subramaniam N, Friedman T, Shek KL. Impact of subsequent pregnancies on pelvic floor functional anatomy. Int Urogynecol J. 2018 Oct;29(10):1517-22.

13. Ajala O, Jensen LA, Ryan E, Chik C. Women with a history of gestational diabetes on long-term follow up have normal vascular function despite more dysglycemia, dyslipidemia and adiposity. Diabetes Res Clin Pract [Internet]. 2015 Dec;110(3):309-14. Available from: https://linkinghub.elsevier.com/retrieve/pii/S0168822715004040

14. Alejandro EU, Mamerto TP, Chung G, Villavieja A, Gaus NL, Morgan E, et al. Gestational Diabetes Mellitus: A Harbinger of the Vicious Cycle of Diabetes. Int J Mol Sci [Internet]. 2020 Jul 15 [cited 2021 May 24];21(14):5003. Available from: 
15. Zhao D, Yuan S, Ma Y, An YX, Yang YX, Yang JK. Associations of maternal hyperglycemia in the second and third trimesters of pregnancy with prematurity. Medicine (Baltimore) [Internet]. 2020 Apr;99(17):e19663. Available from: http://dx.doi.org/10.1097/MD.0000000000019663

16. Hartling L, Dryden DM, Guthrie A, Muise M, Vandermeer B, Aktary WM, et al. Screening and diagnosing gestational diabetes mellitus. Evid Rep Technol Assess (Full Rep) [Internet]. 2012 Oct 19;11(210):1-327. Available from: http://www.pubmedcentral.nih.gov/articlerender.fcgi? artid $=4068111 \&$ tool $=$ pmcentrez\&rendertype $=$ abstract

17. Hod M, Kapur A, Sacks DA, Hadar E, Agarwal M, Di Renzo GC, et al. The International Federation of Gynecology and Obstetrics (FIGO) Initiative on gestational diabetes mellitus: A pragmatic guide for diagnosis, management, and care \#. Int J Gynecol Obstet [Internet]. 2015 Oct [cited 2019 Aug 13];131(S3):S173. Available from: http://doi.wiley.com/10.1016/S0020-7292(15)30007-2

18. Hvidman L, Hvidman L, Foldspang A, Mommsen S, Bugge Nielsen J. Correlates of urinary incontinence in pregnancy. Int Urogynecol J. 2002;

19. Dietz HP. Ultrasound imaging of the pelvic floor. Part II: three-dimensional or volume imaging. Ultrasound Obstet Gynecol [Internet]. 2004 Jun;23(6):615-25. Available from: http://doi.wiley.com/10.1002/uog.1072

20. Arabin B, Baschat AA. Pregnancy: An Underutilized Window of Opportunity to Improve Long-term Maternal and Infant Health-An Appeal for Continuous Family Care and Interdisciplinary Communication. Front Pediatr [Internet]. 2017 Apr 13;5:1. Available from: www.frontiersin.org

21. Mclntyre HD, Catalano P, Zhang C, Desoye G, Mathiesen ER, Damm P. Gestational diabetes mellitus. Nat Rev Dis Prim [Internet]. 2019 Dec 11 [cited 2021 May 24];5(1):47. Available from: https://www.nature.com/articles/s41572-019-0098-8

22. Aguilera J, Semmler J, Coronel C, Georgiopoulos G, Simpson J, Nicolaides KH, et al. Paired maternal and fetal cardiac functional measurements in women with gestational diabetes mellitus at 35-36 weeks' gestation. Am J Obstet Gynecol [Internet]. 2020 Oct 1 [cited 2021 May 24];223(4):574.e1574.e15. Available from: http://www.ajog.org/article/S0002937820304671/fulltext

\section{Figures}




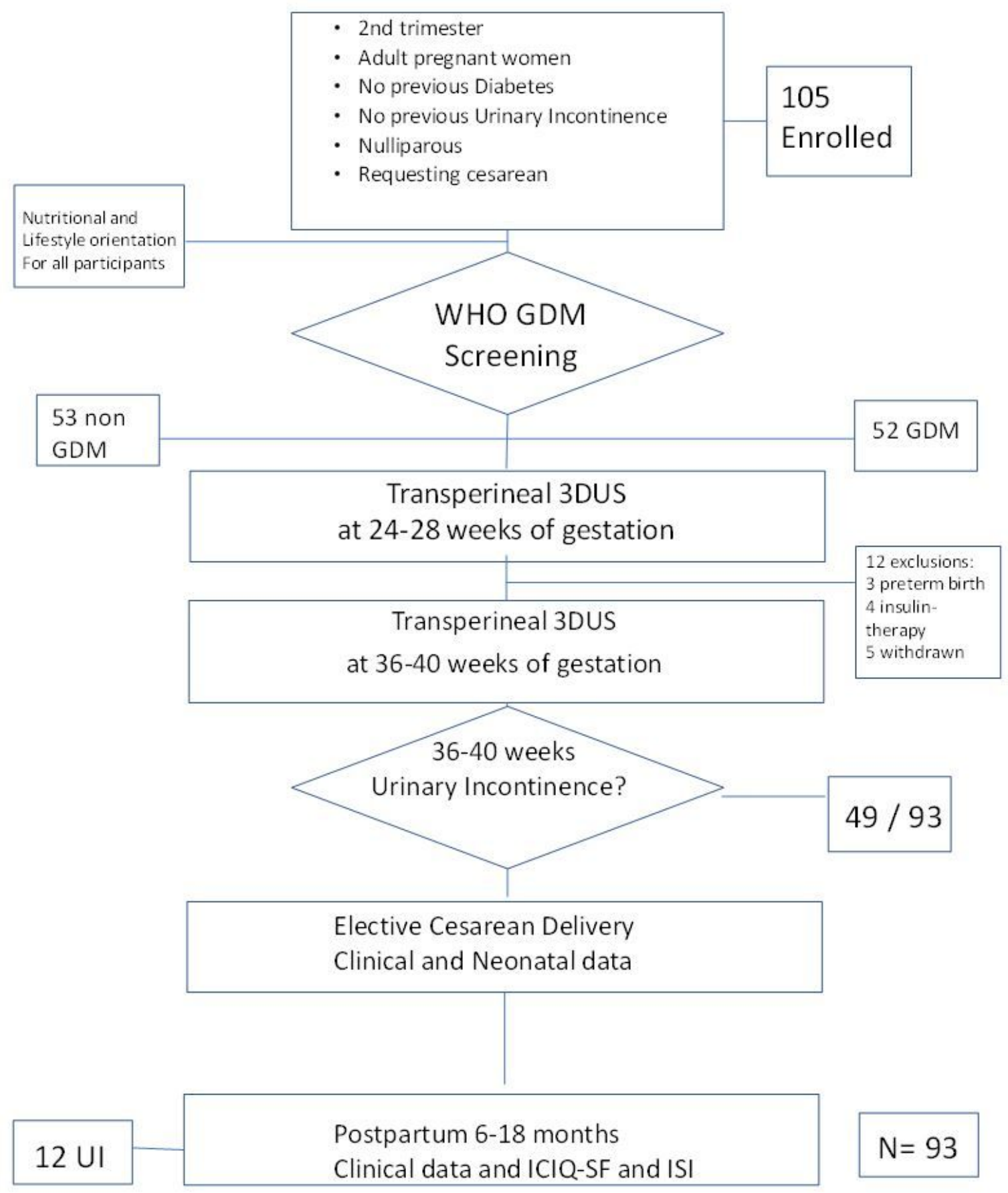

\section{Figure 1}

Flowchart. WHO GDM: Gestational Diabetes Mellitus according to World Health Organization criteria GDM: Gestational Diabetes Mellitus UI: Urinary Incontinence 3DUS: tridimensional ultrasonography ICIQSF: International consultation in incontinence questionnaire-short form ISI: incontinence severity index

\section{Supplementary Files}

This is a list of supplementary files associated with this preprint. Click to download. 
- preliminaryRAWdatabase.xIsx 